\title{
International security after the cold war: utilization of the network technique to prioritize world threats
}

\author{
M. Hamdy ${ }^{1}$, M. Elshafey ${ }^{2}$ \& A. O. Abd El Halim² \\ ${ }^{1}$ International Affairs, Carleton University, Canada \\ ${ }^{2}$ Department of Civil \& Environmental Engineering, Carleton University, \\ Canada
}

\begin{abstract}
The past century witnessed major events of historical magnitude. In the first fifty years of the $20^{\text {th }}$ century, the world suffered two World Wars and several regional conflicts that were very costly in lives and property. A promising future based on information technology and the computer science era provided man with unlimited hope for a healthier future, better job opportunities, medical treatments of serious diseases and much-improved standards of living. The 1990's will be remembered as the years of the death of an old system and the birth of a new one. Those years marked the transition from a world governed by the Cold War issues to new and unclear security arrangements and challenges. The main objectives of this paper are to describe the threats and dangers that would shape the future of the world, to identify the main factors that will bring change to the international order and to utilize engineering tools and techniques in an attempt to study their relative relationship and ranking with respect to each other.
\end{abstract}

Keywords: security, threats, utilization, networks, globalization, information.

\section{Introduction}

The past century witnessed major events of historical magnitude. In the first fifty years of the $20^{\text {th }}$ Century, the World suffered two World Wars and several regional conflicts that were very costly in lives and property. Also, the results of these two Major Wars were the birth of the League of Nations, later the United Nations, the division of the world into two confronting camps, the free world 
under the leadership of the USA and the communist Block led by the former Soviet Union. In addition to the political and military events and forces that shaped the international security of the past century, scientific achievements of significant impact on human evolution and the stability of the world were the mark of the century. From the success of the first nuclear weapon and its historical use on Japan to landing a man on the moon, science and technology offered mixed opportunities and threats to humanity. Promising future based on information technology and the computer era coupled with major discoveries in all fields of science provide man with unlimited hope for healthier future, better job opportunities, medical treatments of serious and threatening diseases to the dreams of much improved standard of livings. At the same time, science also represented a future full of threats and fears of the spread of more accurate and lethal weapons with capabilities of mass destructions (Viotti [1] and Blix and Kauppi [2]).

The past fifty years were years of deterrence and economic development. On one hand, the past fifty years had seen much less military confrontations between the two superpowers. On the other hand, regional conflicts between small to medium size states fighting as proxies for the superpowers were the trade of those past fifty years. The three wars between India and Pakistan, the ArabIsraeli wars, the Cuban crisis, the wars in Africa, the Vietnam war, the GreekTurkish conflict, the war for the Falkland Islands and of course the Russian invasion of Afghanistan. These wars could have easily escalated to a world confrontation where nuclear weapons would have been used, as was the case during the Arab-Israeli war of October 1973. However, fears of nuclear annihilation and the politics of deterrence prevented a confrontation between the two superpowers (Kissinger [3] and Dershowitz [4]).

The main objectives of this paper are to describe the emerging world and the threats and dangers that would shape its future and develop a reliable tool to rank and prioritize the main factors that will bring change to the international order.

\section{Basic factors shaping international security}

In the introduction, a world continually changing is observed. This world is governed and characterized by certain basic forces and factors. These forces and factors are divided or ranked into three levels; global, transitional, and permanently regional. It should be noted that while there are three distinctive ranks or levels it is noteworthy to indicate that there is dependency, interaction and overlapping within each and between the three categories as will be discussed in the following sections.

\subsection{Global factors}

The factors ranked under this category are the ones that have a global or international effect beyond the political boundaries of the interested states or nations. This category is the direct result of the events that shaped the past century. 
Globalization: The fact that the world today faces only one superpower is a factor that could lead to confusion between "globalization" and "Americanization". Both can cause positive as well as negative impacts. Globalization is the free movement of money, people, products, ideas, information, and etc. throughout the world. Furthermore, the free access to information and technology can allow smaller states or potential terrorist group access to weapons of mass destruction.

Global demographic projections: One of the most threatening factors is the uncontrolled growth in world population especially in less-developed and poor countries. World Health Organization and United Nations organized conferences related to this single issue predicted an increase of one Billion persons by the end of the year 2015. This significant increase of humans in countries suffering from limited resources and poor general economic conditions are expected to increase the demands and social problems on the governments and political systems of those nations.

Rapid advances in information: The past century was known as the "American Century" and was marked by the magnificent scientific achievements and discoveries, which America had the lion's share. These achievements were further utilized to develop new and better technologies that helped creating the new revolution of information that became the trademark of the 20 th century.

Vulnerabilities of the evolving global economic infrastructure: The rise of new actors economically and the resulting realignment of economic powers would make the economic future harder to predict and complex to manage. Advancement in technologies and the birth of e-pay and electronic economic infrastructure will certainly have a serious effect on labour and social relationships.

Shortage of energy: Scarcity of proven resources and reserves of conventional sources of energy has become one of the most pressing security issues of the new century. Fossil fuel, oil, is expected to be in high demand and increased American dependence on foreign sources. With countries like China, India, Brazil and South Africa are expected to enter the club of major economic powers the demand for more energy will continue to grow.

Shortage of fresh water resources: While industrial and rich nations are busy trying to control the major sources of oil and other energy assets, most of the world would be willing to fight for what was taken for granted just few years ago, fresh water. It is interesting to note that the price of fresh litter of bottled water cost twice as much of a litter of gas. The world may find itself dragged into an escalating war in search of water. 
Significance of political borders and social boundaries: Advanced technologies such as Internet and use of satellites to broadcast news, distribute information and communicate ideas would cause the gradual breakdown and ultimately disappearance of the physical and social borders separating between peoples of different states and cultures. Religious and cultural ideas and thoughts will be communicated and governments will not be able to protect its Citizens or its borders from such "attack of ideas".

International terrorism: No doubt one of the major features of the new world is the scale and threats presented by states and groups sponsoring terrorism as a tool of their foreign policies. The attacks of the past 15 years and scary pictures of civilian aeroplanes used as missiles to penetrate an undoubting aerospace and attack several strategic targets in the mainland of the USA are strong reminder of the degree of danger and capabilities of criminal groups and states.

North-South disparities in wealth and resource distribution: The gap in wealth, resources and economic growth between the developed (mostly northern) world and the underdeveloped countries (mostly southern) is widening and as a result causing tension between the haves and have-nots. With more than three quarters of the world population live in the southern part of the world serious shortage in almost every aspect of resources and essentials for survival northsouth confrontations and inter-regional tensions will lead to further instabilities.

Weapons of mass destruction and nuclear proliferation: The proliferation of weapons of mass destruction to smaller states and/or groups would continue to be one of the major concerns of the free world for the next 10 to 15 years. Acquisition of nuclear weapons and means to deliver them require special knowledge and strong economies. It is expected that more states would be searching to develop both chemical and biological weapons, which are cheaper and required much less advanced technologies. These countries would present serious danger and true threat to the USA and west (Betts [5]).

\subsection{Transitional factors}

The transitional factors are factors that may influence the international security in the past century and continue to do so to a lesser extent, however, these factors are expected to have no significance on world security once the evolution of this phase is completed.

Ethnic, religious, cultural strife: The past century witnessed several massacres and severe human rights violation in the form of ethnic cleansing or due to religious fanatics. These sad events would continue to provide reasons for conflicts and intervention by the armies of the free world and the risk of escalating the war to become a world war, as was the case in the Balkan war. However, as the world regains its stability and the governments that are willing to violate world order are aware of the heavy price of committing such crimes it is expected that this factor would become less significant (Gorenberg [6]). 
Regional conflicts: Many conflicts remain unresolved and carrying with them the threat of wide war where many countries get involved. The wars and subsequent occupation of Iraq, Afghanistan, the Arab-Israeli conflict and the attempts of China to unify both the motherland with Taiwan can lead to large scale military confrontations (Chubin [7]).

Other major powers: Another unsettling factor is the evolving of other major powers either to compete with the USA to become a superpower, or ones on the decline and could cause instability in global security. Unified Europe, Japan, China and India are on the rise. On the other hand, declining superpower such as in the case of Russia where its government is caught between the attempt to restore a lost glory or to accept the new facts of becoming a major power instead can become a serious factor to destabilize world security (Barnett [8]).

\subsection{Permanently regional factors}

These factors are generally influencing regional zones and they are of permanent nature and could occur periodically with far reaching impacts. They include natural disasters such as earthquakes, major floods, and hurricanes and largescale ice storms and health and environmental issues.

Natural disasters, environmental issues and pollutions: The world witnessed several natural disasters over the past decades with several hitting the heartland of the United States. Also, the world witnessed several powerful earthquakes, a devastating tsunami, few major floods, severe cases of droughts, and tens of hurricanes and tornados. Natural disasters will continue to occur all over the world, often with little or no warning. Human activities including uncontrolled increase in populations, pollution, industrialization, deforestation and poor waste management will lead to affecting the global climate and weather patterns thus influencing international security.

Health issues/ infectious diseases: Sharp increase in world populations especially in poor and less-developed nations in the era of free travel of people and globalization of economies and information will increase the risks of spread of epidemic diseases with global consequences. The spread of HIV/Aids, the Chinese Sars, mad-cow disease and Birds' Flue from their local origins to almost the entire world in amazing speeds is indeed an eye opener especially with no effective way to control their spread (Copson [9]). These events showed the risks and threats resulting from globalization and rapid demographic changes.

\section{Analyses and Interdependency}

A detailed description of the main factors and forces shaping international security and its future was presented and discussed. The second objective of this paper is to identify and rank the dependency between the various factors and their interaction in order to evaluate their relative importance. It must be 
emphasized however that we do not have the accumulated evidence to understand the many complex social, political, and military interactions that produced such rapid international and domestic changes. International security is incredibly diverse, stretching from peace studies to war analysis, from rational choice to logical policy, from physicists to psychologists, from liberalist to radicals, from the past to the future. During the Cold War era the political agenda was focused on the superpowers rivalry. The new era has to deal with new issues and arrangements. A good example is the connection between environmental problems, resource scarcities, and regional conflicts. Subsequently, this section is divided into two parts. The first deals with the relationships and interdependencies between the various factors and forces while the second deals with the criterion for establishing the importance of each of the discussed factors.

\subsection{Network of interdependencies}

The relationship between the various factors and their interdependencies could be recognized through the analysis of each factor and its influence on world peace or instability. We start with "globalization" since it is the most recognized term in today's international security. Globalization suggests transforming the world into small friendly village where citizens from all backgrounds could have free and equal access to trade, travel and information and technology. Clearly, this accessibility when falls to the wrong hands can expose world security and peace to unpredictable dangers. Hence, a case of interdependency does exist between globalization and international terrorism. One of the main objectives of international terrorism is the possession of a weapon of mass destruction or the knowledge of its production in order to exert maximum damage on countries and citizens opposing to their terrorism methods and goals. Thus, interdependency is present between international terrorism, globalization, weapons of mass destruction and rapid advances in information and technologies. An approach to assist performing the analysis is to present each of the factors by a "node" and examine the interdependencies between them. When dependency exists an arrow is drawn connecting between the two nodes of influence and thus provides a visualized evidence of the relationship between the two or more factors. Figure 1 illustrates the analysis discussed in this section.

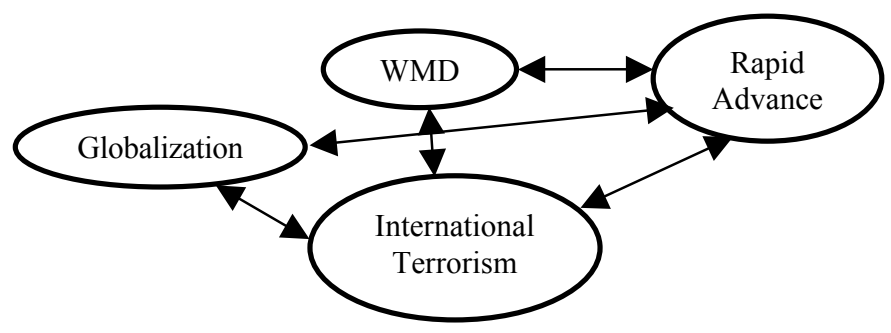

Figure 1: $\quad$ Establishment of network of interdependencies. 
The arrows in the Figure indicate the existence of interdependencies between international terrorism and the other three factors, while there is no interdependency between globalization and weapons of mass destruction. The methodology is followed to examine other dependencies and relationships between the factors introduced in section 2.1 above. For example, the next factor added is the ethnic and religious strife. Ethnic and religious and cultural strife can easily escalate to create regional conflicts. Also, the advancement in information and technology would speed up the communication and transmission of thoughts and ideas that governments and states had been able to keep from their citizens before the current technologies became available. The balls of influence and interdependencies grow and multiply at the same time it provides a visual animation of the discussed principle. It can be easily seen that relationship exists between Ethnic and religious strife and international terrorism. There is sufficient evidence in the Middle East and several Muslim countries where the spread of western and American ideas and thoughts resulted in major demonstrations and threats of assassination. Most recently, the use of cartoons in a Danish newspaper to picture the prophet Mohamed as a promoter of war and terror resulted in bloody demonstrations as far away as Pakistan and Indonesia with several thousand Muslims acting hysterically while threatening violence and unrest. These would have been hard to occur without the invention of satellites, Internet and of course CNN! When the Significance of political borders and social boundaries is analyzed in terms of interdependencies and relationships to other factors it is now easier to trace the path of influence and range of factors affecting this factor and affected by it. When this factor is considered several others are becoming more significant. The immediate effect will be the spread or attack of "foreign ideas", thus religious and cultural strife can result. When the attack of the foreign ideas persist and the state or the government is helpless to stop or resist such flow of information, unrest and escalation of violence will result, ultimately leading to acts of terrorism by groups or individuals, or all out military confrontations in the form of regional conflicts. And a new set of nodes and arrows of influence will be added to the main network until a full figure is completed as can be observed between figures 1 and 2 .

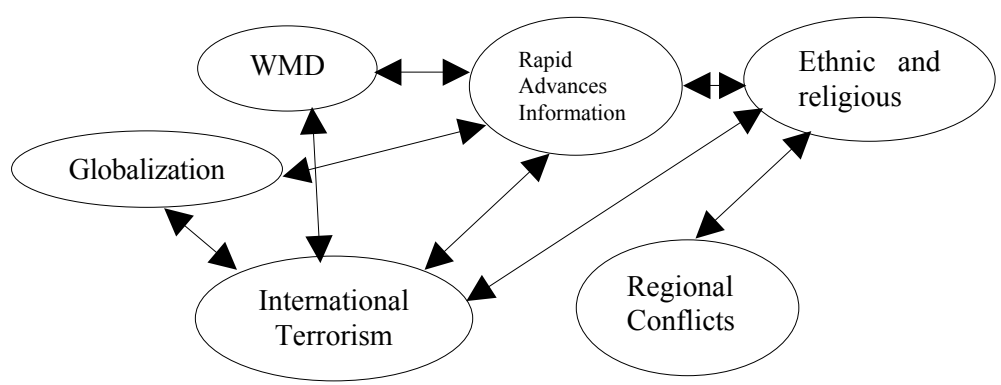

Figure 2: The evolution of the interdependency and influence diagram. 


\subsection{Impact of the interdependencies and relationships}

The analysis performed above showed that selecting a factor and identifying an action will lead to strings attached to other factors thus the "network of influence" is established and the nodes would represent the factors while the arrows would indicate the influence and dependencies. It is important that we draw a line between the factor, its influence and the outcome or impact of the relationship. The established network is by no means a network of threats and dangers to stability and world security. In certain condition a change of one node and replacing it with another may result in the strengthening of world security and improving its overall stability. A good example is the replacement of the factor "ethnic and religious strife" with "Natural disasters, environmental issues and pollutions" then one can observe a network of nodes and arrows that would result in strengthening world peace and stability. Clearly, when this node is replaced the value of advanced technology and information becomes very important and critical. We all remember the speed with which pictures of the recent tsunami were transmitted in real time to the majority of states around the world and how this resulted in a very effective and quick response to the calls for assistance and emergencies.

\subsection{Importance of factors and influences}

Policy makers, political analysts and researchers usually need instruments to measure and in turn rank the weight of a specific factor or its influence relative to another factor or influences. Also, it is important that a method can be established where a reliable measure can be applied without complexity. Any threat, a danger or an opportunity has three unique characteristics. They are the intensity of its effect or impact, the range of its influence and the frequency of its occurrence. The intensity of a factor can be quantified by the amount of change it can cause. The changes could be positive or negative depending on the factor and the prevailing international conditions. The range of the factor is measured by the space that the application of the factor would cover or influence. The frequency of applying the factor over a specific period of time is an indication of the significance of the factor in question. When we complete the "network of interdependencies", a simple count of the number of the arrows connected to the node should provide a reasonable evidence of the significance or weight and rank of the factor at hand. This step is accomplished by establishing a chart deduced from information given by the "network of independencies" as shown in Table 1. The results given in the chart or Table show that the most important factors to shape world security and affect its stability are the rapid advances in information and technology and regional conflicts, each factor was influencing and /or influenced by 6 other factors.

\section{Conclusion and remarks}

This paper presents an analytical approach to assess the importance and relative ranking of factors and forces affecting global security and world stability. The 
paper provides a simple method based on visual representations utilizing the method of nodes and arrows to establish a "network of interdependencies or influences". The network provides the foundation to establish a table of ranking the factors relative to each other based on their influence, range and frequencies.

Table 1: $\quad$ Ranking of factors affecting international security.

\begin{tabular}{|c|c|c|c|c|c|c|c|c|c|c|c|c|c|c|}
\hline & $\begin{array}{l}1 \\
\dot{G}\end{array}$ & $\begin{array}{l}2 \\
\dot{G}\end{array}$ & $\begin{array}{l}3 \\
\dot{R}\end{array}$ & $\begin{array}{l}4 \\
\dot{\mathrm{V}}\end{array}$ & $\begin{array}{l}5 \\
\dot{S}\end{array}$ & $\begin{array}{l}6 \\
\dot{\mathrm{P}}\end{array}$ & $\begin{array}{l}7 \\
\text { I }\end{array}$ & $\begin{array}{l}8 \\
\dot{\mathrm{D}}\end{array}$ & $\begin{array}{l}9 \\
\text { W }\end{array}$ & $\begin{array}{l}10 . \\
\mathrm{E}\end{array}$ & $\begin{array}{l}11 . \\
\mathrm{R}\end{array}$ & $\begin{array}{l}12 \\
\mathrm{O}\end{array}$ & Sum & Rank \\
\hline 1.Globalization & & $\mathrm{X}$ & $\mathrm{X}$ & $\mathrm{X}$ & & & $\mathrm{X}$ & & & & & & 4 & $3^{\text {rd }}$ \\
\hline $\begin{array}{l}\text { 2.Global } \\
\text { demographic }\end{array}$ & $X$ & & & & & & & $X$ & & $\mathrm{X}$ & $X$ & & 4 & $3^{\text {rd }}$ \\
\hline $\begin{array}{l}\text { 3.Rapid advances } \\
\text { in information }\end{array}$ & $\mathrm{X}$ & & & $X$ & & $X$ & $X$ & & $X$ & $\mathrm{X}$ & & & 6 & $1^{\text {st }}$ \\
\hline $\begin{array}{l}\text { 4.Vulnerabilities } \\
\text { of the evolving } \\
\text { global economic } \\
\text { infrastructure }\end{array}$ & $\mathrm{X}$ & & $X$ & & & & & & & & & & 2 & $4^{\text {th }}$ \\
\hline $\begin{array}{l}\text { 5.Shortage of } \\
\text { Energy }\end{array}$ & & & & & & & & $\mathrm{X}$ & & $\mathrm{X}$ & & & 2 & $4^{\text {th }}$ \\
\hline 6.Political borders & & & $\mathrm{X}$ & & & & & & & $\mathrm{X}$ & & & 2 & $4^{\text {th }}$ \\
\hline $\begin{array}{l}\text { 7.International } \\
\text { Terrorism: }\end{array}$ & $\mathrm{X}$ & & $\mathrm{X}$ & & & & & $\mathrm{X}$ & $\mathrm{X}$ & $\mathrm{X}$ & & & 5 & $2^{\text {nd }}$ \\
\hline $\begin{array}{l}\text { 8.Disparities in } \\
\text { wealth }\end{array}$ & & $\mathrm{X}$ & & & $X$ & & $X$ & & & & $\mathrm{X}$ & & 4 & $3^{\text {rd }}$ \\
\hline $\begin{array}{l}\text { 9. Weapons of } \\
\text { Mass }\end{array}$ & & & $\mathrm{X}$ & & & & $X$ & & & & $\mathrm{X}$ & $\mathrm{X}$ & 4 & $3^{\mathrm{rd}}$ \\
\hline $\begin{array}{l}\text { 10.Ethnic, } \\
\text { religious, } \\
\text { cultural strife }\end{array}$ & & $\mathrm{X}$ & $X$ & & & $X$ & $\mathrm{X}$ & & & & & & 4 & $3^{\text {rd }}$ \\
\hline $\begin{array}{l}\text { 11.Regional } \\
\text { conflicts }\end{array}$ & & $\mathrm{X}$ & & & $X$ & & $\mathrm{X}$ & & $\mathrm{X}$ & $\mathrm{X}$ & & $\mathrm{X}$ & 6 & $1^{\mathrm{st}}$ \\
\hline $\begin{array}{l}\text { 12.Other Major } \\
\text { Powers }\end{array}$ & & & & & & & & & $\mathrm{X}$ & & & & 1 & $5^{\text {th }}$ \\
\hline
\end{tabular}

Next factor was international terrorism. It is important to note that the most important factor shaping the world security today is one that indeed affects the life and day-to-day standard of living of almost the entire world; rapid advances in information and technology. It is also expected that this single factor will continue to affect the world stability and security in the future. One of the most important observations is that the consideration of new factors such as advanced information technology and globalization certainly helped changing the influence of regional conflicts in the new century and brought it closer to international terrorism, which is supported by the famous expression that vision remains blurry in the current era. Other rankings could be obtained from the Table. It is important to note that the least important factor was the other major powers. The roles of Russia, China, Europe, Japan and India on world security 
and stability have been decreased to be the lowest. This could be explained in terms of the supremacy of the United States and the fact that most of these major powers seek to cooperate and follow the lead of the United States rather then confronting it or challenge its world dominance.

\section{References}

[1] Viotti, P.R. \& Kauppi, M.V., International Relations and World Politics, Third Edition. Upper Saddle River, New Jersey 07458, 2006.

[2] Blix, H., Ways of countering WMDs: Pre-emptive War and CounterProliferation, or International Co-Operation and Disarmament, Proc. of the 6th International Security Conference, Switzerland, pp.37 to 45, 2004.

[3] Kissinger, H., Crisis: The Anatomy of Two Major Foreign Policy Crises, Simon \& Schuster, Rockefeller Centre, New York, 2003.

[4] Dershowitz, A., The Case for Peace: How the Arab-Israeli Conflict Can Be Resolved, John Wiley \& Sons, Inc., 2005.

[5] Betts, R., Weapons of Mass Destruction, Columbia International Affairs Online (CIAO), New York, US, pp.11, Jan 2002.

[6] Gorenberg, G., The End of Days" Fundamentalism and the Struggle for the Temple Mount, The Free Press, New York, 2000.

[7] Chubin, S., The Wider Middle East: After Iraq and the War on Terror, Proc. of the $6^{\text {th }}$ International Security Conference, Switzerland, pp. 118 to 120, October 2004.

[8] Barnett, T.P., The Pentagon's New Map: Blueprint for Action- a Future worth Creating, G.P. Putnam's Sons, New York, 2005.

[9] Copson, R.W., Aids in Africa, Congressional Research Service, CRS Issue Brief for Congress, pp. 19, June 2005. 